\title{
Hemispheric object naming and interhemispheric transfer functions in reading disordered subjects
}

\author{
JOAN N. KADERAVEK ${ }^{1}$ and MICHAEL P. RASTATTER ${ }^{2}$ \\ 'School of Education, University of Michigan, Ann Arbor, Michigan, USA; ${ }^{2}$ Department of \\ Communication Sciences and Disorders, East Carolina University, Greenville, North Carolina, \\ USA
}

\begin{abstract}
This study measured unilateral, tachistoscopic naming reaction times of normal and reading disordered children to objects representing two levels of picture vocabulary age. Results of an ANCOVA procedure on the latency data showed main effects for group and stimuli, but not visual field. The latency results suggested parallel, central picture naming operations for each group, with the reading disordered children evidencing significantly longer naming reaction times to each level of stimuli. Arc Sine transformed error data were submitted to an analysis of co-variance procedure and showed a significant stimuli $\times$ group interaction. Post hoc tests showed accelerated error rates following right hemispheric stimulation, suggesting anomalous interhemispheric transfer of visual images in the present group of reading disordered children. In addition, left hemispheric stimulations produced significantly more naming errors for the reading disordered subjects as compared to the normal children. Such findings may suggest that a group of higher-ordered processing operations may accompany reading disorders.
\end{abstract}

KEY WORDS: Hemispheric processing, Interhemispheric transfer, Object naming, Reading disordered children, Reaction time

\section{INTRODUCTION}

A series of studies have been undertaken in an attempt to investigate the anatomical structure of the dyslexic brain. Using both autopsy data and magnetic resonance imaging techniques, several cortical, anatomical variations have been reported in the brains of dyslexic subjects (see Flowers 1993; Galaburda 1989; Galaburda, Sherman, Rosen, Aboitiz \& Geschwind 1985; Steinmetz \& Gallaburda 1991). Cortical anomalies such as the presence of myelinated scars, disorganization of the cortical plate, and symmetry of the usually asymmetrical planum temporale, a cortical area involved in language processing tasks needed for reading, have been reported (Galaburda 1989; Hynd, Marshall \& Semrud-Clikeman 1991; Steinmetz \& Gallaburda 1991). The later finding, symmetry of the plana temporale, has been interpreted to be associated with increased corpus callosum connectivity, and, as such, may be related to dyslexia. Such a position was based on the finding that symmetrical left and right hemispheric cortical areas are more intensely connected than are asymmetrical areas of the brain (Rosen, Sherman \& Galaburda 1989).

Reading and Writing: An Interdisciplinary Journal 8: 161-169 (April 1996)

(C) 1996 Kluwer Academic Publishers. Printed in the Netherlands. 
In addition to the anatomical data, recent neuropsychological evidence has emerged indicating that aberrations in interhemispheric transfer of information in reading disordered children may be influential in their disorder (Broman, Rudel, Helgott \& Krieger 1986; Davidson, Leslie \& Saron 1990). Based on this literature, two possible underlying mechanisms have been hypothesized related to interhemispheric transfer functions in reading disordered children. The first includes a signal processing time theory which indicates that the time associated with the exchange of stimuli from the right to left hemispheres may be too brief in reading disordered children, thereby encroaching on analytic, left hemispheric functions (Davidson, Leslie \& Saron 1990). Such a position was based on an experiment where manual reaction times of a group of dyslexic readers were measured to unilaterally presented non-linguistic visual stimuli. Davidson et al. (1990) showed that faster interhemispheric transfer times were associated with poorer performance on measures of language and reading for the dyslexic subjects. These data were interpreted by Davidson et al. (1990) to suggest that anomalies in the speed of interhemispheric transfer of visual information may be related to reading and language disorders in certain sub-groups of children.

A second theoretical prospective exists suggesting that some form of interhemispheric signal degrading occurs that seems to interfere with efficient, right-to-left hemisphere processing of visual information in reading disordered children. Two earlier studies provide data that appear to support a signal degrading, interhemispheric transfer deficit theory in dyslexic children. Gross, Rothenberg, Schottenfeld \& Drake (1978) measured 'duration thresholds' (stimulus presentation speeds designed to produce various levels of naming accuracy) to lateralized letters. They found that, as compared to the normal children, the disabled readers produced longer stimulus duration thresholds in both visual-half fields in order to achieve parallel accuracy levels. In addition, the disabled readers showed greater differences between stimulus detection thresholds for the left versus right visual-half fields. While the authors believe that such asymmetries in the stimulus detection thresholds may reflect anomalous interhemispheric transfer functions in the reading disabled children, the increased variance in their data suggested that other central processing factors may be involved in dyslexia as well. Additionally, as part of a larger study, Yeni-Komshian, Isenberg \& Goldberg (1975) measured accuracy rates of poor readers to unilaterally presented numerals and digits written as words. Pertinent findings showed that left visual field presentations produced elevated error rates, suggesting that either degraded right hemispheric processing occurred at some level, or less efficient interhemispheric transfer of visual information accounted for the data.

Such theoretical positions, however, were based on data derived from stimulus-response paradigms that required either simple signal-detection processing mechanisms or early-level linguistic subsystems incapable of assessing higher-ordered language processing events. As such, further research is called for investigating interhemispheric transfer patterns in reading disordered 
children for higher-ordered linguistic stimuli, such as images or pictures representing different levels of vocabulary age. Since reading functions and vocabulary development are intimately related (Bus, van Ijzendoorn \& Pellegrini (in prep.); Nino 1980; Whitehurst, Falco, Lonigan, Fischel, DeBarvshe, Valdez-Menchaca \& Caufield 1988), tests of hemispheric transfer of stimuli representing various vocabulary levels in reading disordered children appears warranted. Such information should broaden our understanding of interhemispheric transfer mechanisms and their relationship to linguistic functions in children who are reading impaired.

The purpose of the present study was to measure unilateral, tachistoscopic naming reaction times of normal and reading disordered children to pictures representing different levels of vocabulary-age. Such a procedure will be capable indexing interhemispheric transfer functions underlying verbal output since phonemic recoding mechanisms located in the left hemisphere must be accessed prior to a verbal response. As such, signal degrading difficulties associated with interhemispheric transfer deficits will be directly observable by analyzing naming reaction times and error patterns following stimulus input to each visual half-field.

\section{METHOD}

Subjects. Thirty reading disabled subjects (mean age 9.3 years; range 8.6-9.4 years) and a matched sample (age and sex) of normal subjects were administered the experimental procedures. Reading disabled subjects were selected by their referral to, and acceptance into, a Reading Center, a diagnostic and treatment program for disabled readers at a Midwest university. Children are enrolled into the Reading Center based on a diagnostic pre-assessment. This assessment includes the administration of two subtests of the Woodcock Reading Mastery Test-Revised (WRMT-R) (Woodcock 1987) and the Peabody Picture Vocabulary Test - Revised (PPVT-R) (Dunn \& Dunn 1981). The standard score equivalent on the PPVT-R for the reading disabled children was 97.11 , while the corresponding standard score equivalent for the normal subjects was 107.50 . The mean age equivalent score on the World Identification Subtest for the reading disabled subjects was 7 years 11 months (an average of 2 years 4 months below their chronological age), while the normal subjects obtained an average age equivalent score of 9 years 8 months (an average of 3 months above their chronological age). The mean age equivalent score on the Word Attack Subtest was 6 years 11 months for the reading disabled children ( 3 years 5 months below their chronological age), while the corresponding score was 11 years 8 months for the normal children ( 2 years 2 months above their chronological age). Normal subjects were randomly selected from a local elementary school in Northwest Ohio. All subjects were evaluated using the Classification of Hand Preference by Association Analysis (Annett 1970) and showed a right-hand preference. 
Stimuli. Stimuli were a series of 16 line drawings representing picture vocabulary items taken from the Boston Naming Test (Goodglass \& Kaplan 1983). Items corresponded to picture vocabulary ages of 5.5 years (Level 1) (bed, tree, pencil, house, whistle, scissors, flower, saw) and 10 years of age (Level 11) (harp, hammock, pelican, pyramid, muzzle, unicorn, funnel, knocker). All pictures were hand sketched by a professionally trained artist. The drawings fit within a $1.5 \mathrm{~cm}$ square. The stimulus pictures were then affixed to an index card. All index cards were photographed and made into slides to fit the slide projector. The stimuli subtended visual angles between 3 and 4 degrees from the central fixation point to the lateral periphery for pictures in both the left and right visual fields. All stimuli were presented unilaterally to both the left and right visual fields.

Instrumentation. The visual stimuli was presented unilaterally to both the right and left visual fields by a tachistoscope (Lafayette Model 42011-A) set at an exposure duration of $100 \mathrm{msec}$. Simultaneously with onset of illumination, the tachistoscope's presentation timer was activated by a second digital timer (CMV, Model 7078) accurate to $1 \mathrm{msec}$. The timer was stopped by a signal from a voice-operated relay (Grason-Stadler, Model E7300-1) activated by a microphone (Grason-Stadler, E7300A-2) after the subject responded to the picture stimulus. This gave a naming reaction-time value for that particular stimulus (see below).

Object recognition procedure. Each subject was instructed to focus on a circular fixation point presented under the constant illumination mode of the tachistoscope. It was explained that a series of line drawings would appear either to the right or left of the fixation circle. The subjects task was, as quickly and accurately as possible, to speak the name of the picture into the microphone (located approximately $10 \mathrm{~cm}$ from the subject's mouth). The order of stimulus presentation was randomized, using the criterion that identical pictures would not appear adjacent to each other in a direct sequence. The order of presentation was identical for all subjects.

\section{RESULTS}

Reaction time data. The reaction time data were submitted to an analysis of covariance (ANCOVA) procedure in an attempt to adjust for the effects of PPVT average differences between the RD and normal children. Table 1 presents the adjusted means and standard deviations for each independent variable for the RD and normal children. Results of the ANCOVA showed that the covariate (x PPVT scores) did not account for a significant portion of the variance $(p>0.05)$. After adjusting for the covariate, the analysis showed significant main effects for Group $[\mathrm{F}(1,57)=16.64 ; p<0.01]$, and 
Table 1. Means and standard deviations for naming reaction times as a function of group, visualfield and picture vocabulary-age level

\begin{tabular}{lrr}
\hline Variable & Mean & SD \\
\hline Group* & & \\
$\quad$ Disordered readers & 1.091 & 225 \\
$\quad$ Normal readers & 933 & 164 \\
Stimuli* & & \\
$\quad$ Level I & 890 & 191 \\
Level II & 1.135 & 201 \\
Visual field & & \\
$\quad$ Left & 1.044 & 221 \\
Right & 980 & 198 \\
\hline
\end{tabular}

* Means significantly different.

stimuli $[\mathrm{F}(1,57)=24.32 ; p<0.01]$, but not for visual field $[\mathrm{F}(1,57)=1.38$; $p>0.05]$. All interactions were nonsignificant $(p>0.05)$.

Error data. An Arc Sine transformation was applied to the error data and submitted to an ANCOVA procedure to test the significant main effects and interactions among variables. The analysis showed a nonsignificant covariate $(p>0.05)$ and that the main effect for group $[\mathrm{F}(1,72)=41.24 ; p<0.01]$, stimuli $[\mathrm{F}(1,72)=42.30 ; p<0.01)$ and visual field $[\mathrm{F}(1,72)=4.16 ; p<0.05]$ were significant. Additionally, the visual field $\times$ group interaction was significant $[\mathrm{F}(1,72)=6.20 ; p<0.05]$, while remaining interactions were nonsignificant $(p>0.05)$. Figure 1 displays the visual field $\times$ group interaction. Tukey post hoc tests showed that significant differences in error rate existed between groups as a function of each visual-half field $(p<0.01)$. Additionally, significant differences existed between the two visual fields for the reading disordered group $(p<0.01)$, but not for the normal reading subjects $(p>0.05)$.

\section{DISCUSSION}

The results of the current study showed that the main effect for stimulus level (picture vocabulary-age) was significant. Stimuli corresponding to early levels of vocabulary acquisition were named significantly faster than those acquired at a later age. The fact that the stimuli $\times$ group interaction was nonsignificant suggests that central, object naming functions were parallel for the two groups of children.

It has been demonstrated that the recognition of visual information results from the operation or interaction of several subsystems or modules over a 


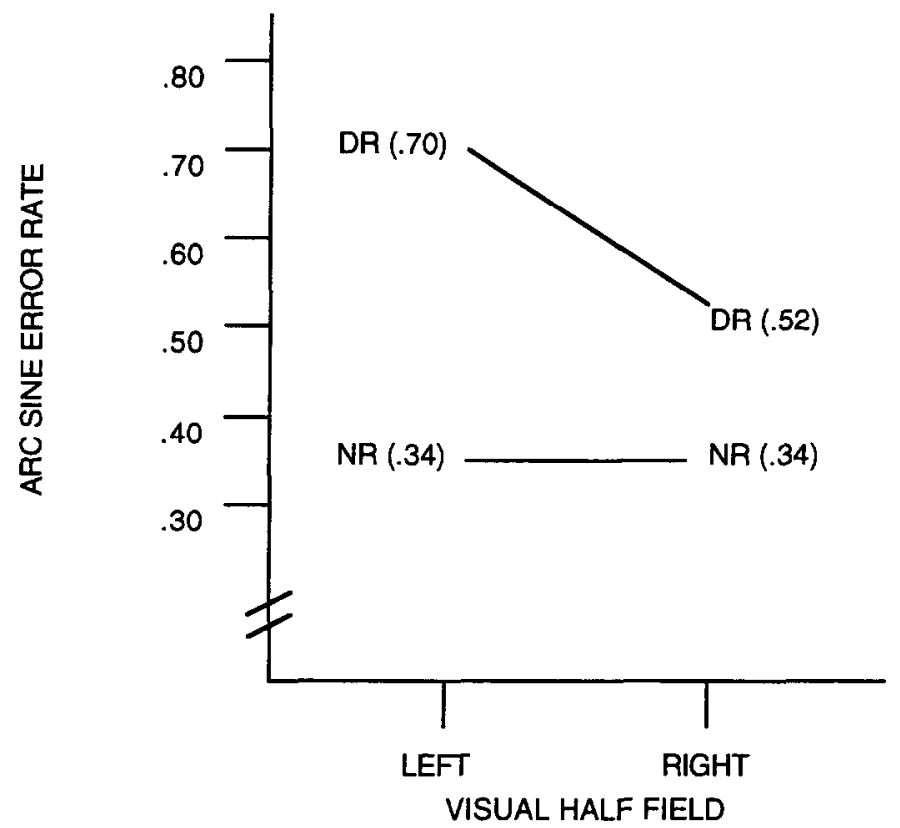

Figure 1. Significant interaction obtained between the group and visual field variables. DR, disordered readers; NR, normal readers.

given period of time (Chiarello, Nuding \& Pollock 1988; Riddoch \& Humphreys 1987). Riddoch \& Humphreys (1987) forwarded a processingstage model operationalizing the dynamics involved in picture-naming tasks. They argue that initially the image of a picture must access a lower-level perceptual processing stage where figure-ground discrimination and local and global form discriminations are integrated. Prior to naming, however, three additional, higher level representations must be accessed in a cascading manner to formulate a verbal response. These include a structural descriptive level where knowledge of object form (the object's parts relative to its major axis) is accessed, a semantic representation system concerned with functional and associative object characteristics, and finally, a phonological level responsible for output-naming functions.

The activation of the naming cascade, however, may be influenced by certain factors. That is, it has been demonstrated that name frequency (the frequency of occurrence in the language) influences naming reaction times to objects from structurally distinct categories (Riddoch \& Humphreys 1987). Objects with a high frequency of occurrence in the language are named significantly faster as compared to objects corresponding to lower frequencies. Since the vocabulary-age levels of our stimuli varied inversely with the frequency of the object names (Francis \& Kucera 1982), it is suggested that both groups performed the current naming task in a manner consistent with the neuropsychological principles defining the Cascade Model. Under normal 
conditions, the time involved in performing structural description and semantic level resolution influences directly those variables impacting later stages of analysis, such as object-name frequency, or, for the current study, vocabularyage level. Specifically, Riddoch \& Humphreys (1987) indicate that structurally-distinct objects are capable of accessing structural and semantic information quite rapidly. Due to rapid access, there is less time for late representations to be partially activated through the cascade, resulting in marked effects on response latency. As such, based on the principles of the Cascade Model, it would appear that central, verbal mediation processes of the disordered and normal readers were parallel.

It must be noted, however, that while the cascading events involved in the picture naming process were functionally intact for the reading disordered children, the latency analysis showed that the time involved in performing naming cascades was significantly slower than the normal subjects. Such findings suggest that the modular interactions required to name objects were impeded at some level within the cascade. These results, however, are not surprising since it has been shown that pictures of objects with more frequently occurring names are labeled more rapidly than pictures of objects with less frequently occurring names (Leonard, Nippold, Kail \& Hale 1983), and the naming reaction times of dyslexic children are more latent than those of normal children (Wolf, Michel \& Ovrut 1990). As such, tests of modularrelated processing activity are warranted if attempts to further understand these issues are to be made.

Results of the error analysis showed a significant interaction between the group and visual field variables (Figure 1). Post-hoc tests showed that the reading disordered children's error rates were significantly increased following right visual field input as compared to the normal subjects. While these data are consistent with the literature showing that reading disordered subjects experience elevated levels of naming errors, the current findings suggest that a left hemispheric picture naming deficit may accompany reading disorders.

The remaining finding, that error rates increased significantly following left visual field stimulations as compared to right visual field input for the reading disordered group, provides some interesting insights pertaining to right-to-left interhemispheric communication of visual information. Such findings are consistent with a theoretical perspective suggesting the possibility that an interhemispheric, signal degrading transfer deficit may be operational in certain types of reading disordered children. Zaidel (1983) has suggested that when visual information must cross the corpus callosum prior to analysis, as is in the case of the current interhemispheric transfer interpretation, signal fidelity may be altcred resulting in a loss of certain features necessary to perform discriminations. As such, accelerated error rates following right hemispheric stimulation may suggest anomalous interhemispheric transfer of visual images in the present group of reading disordered children. What is striking about the data is the fact that error rate was not affected in the normal 
children following left visual field input, suggesting efficient, nondegraded, interhemispheric transfer functions for the current stimuli.

While difficulties were noted in the interhemispheric transfer of the current visual stimuli in the reading disordered children, information relative to which visual features were subjected to distortion is not known. Specifically, error producing, or visual confusion paradigms, would produce data suggesting which level of the picture naming cascade is negatively impacted through the course of interhemispheric transfer. Once this level of information is available, treatment programs may be developed to better remediate reading disorders that are associated with interhemispheric transfer deficits.

Finally, while the present findings suggest that reading disordered children evidence normal picture-naming cascading events, they concurrently manifest a left hemispheric object naming access problem at some level within the cascade. Right visual-field reaction time data support the first assumption, while the later position is upheld by the right visual-field error patterns. In addition to these processing anomalies, it appears also that the reading disordered children exhibit a signal degrading, interhemispheric transfer deficit that may interfere with right-to-left hemisphere visual language processing operations. In essence, the current study indicates the reading disordered children may, in fact, possess a constellation of central processing disorders that negatively influence higher-ordered linguistic and reading processes.

\section{REFERENCES}

Annett, M. (1970). A classification of hand preference by association analysis, British Journal of Psychology 61: 303-321.

Broman, M., Rudel, R. G., Helgott, E. \& Krieger, J. (1986). Inter- and intrahemispheric processing of letter stimuli by dyslexic children and normal readers, Cortex 34: 302-313.

Bus, A. G., van Ijzendoorn, M. H. \& Pelligrini, A. D. (in preparation). Storybook reading makes for success in learning to read: A meta-analysis on the integrational transmission of litcracy.

Chiarello, C., Nuding, S. \& Pollock, A. (1988). Lexical decision and naming asymmetries: Influence of response selection and response bias, Brain and Language 34: 302-314.

Davidson, R. J., Leslie, S. C. \& Saron, C. (1990). Reaction time measures of interhemispheric transfer time in reading disabled and normal children, Neuropsychologia 28: 471-485.

Dunn, L. \& Dunn, L. (1981). Peabody Picture Vocabulary Test-Revised. Circle Pines, MN: American Guidance.

Flowers, D. (1993). Brain basis for dyslexia: A summary of work in progress, Journal of Learning Disabilities 26: 575-582.

Francis, W. N. \& Kucera, H. (1982). Frequency analysis of English usage: Lexicon and grammar. Boston, MA: Houghton Mifflin.

Galaburda, A. M. (1989). Ordinary and extraordinary brain development, Annals of Dyslexia 39: $67-80$.

Galaburda, A. M., Sherman, G. F., Rosen, G. D., Aboitiz, F. \& Geschwind, N. (1985). Developmental dyslexia: Four consecutive patients with cortical anomalies, Annals of Neurology 18: $222-233$.

Goodglass, H. \& Kaplan, E. (1983). The assessment of aphasia and related disorders. Philadelphia, PA: Lea \& Febiger. 
Gross, K., Rothenberg, S., Schottenfeld, S. \& Drake, C. (1978). Duration thresholds for letter identification in left and right visual fields for normal and reading-disabled children, Neuropsychologia 16: 709-715.

Hynd, G. W., Marshall, R. M. \& Semrud-Clikeman, M. (1991). Developmental dyslexia, neurolinguistic theory and deviations in brain morphology, Reading and Writing: An Interdisciplinary Journal 3: 345-362.

Leonard, L. B., Nippold, M. A., Kail, R. \& Hale, C. A. (1983). Picture naming in languageimpaired children, Journal of Speech and Hearing Research 26: 609-615.

Nino, A. (1980). Picture book reading in mother-infant dyads belonging to two sub-groups in Israel, Child Development 51: 587-590.

Riddoch, M. J. \& Humphreys, G. W. (1987). Picture naming. In: G. W. Humphreys \& M. J. Riddoch (eds.), Visual object processing: A cognitive neuropsychological approach (pp. 107-143). Hillsdale, NJ: Erlbaum.

Rosen, G. D., Sherman, G. F. \& Galaburda, A. M. (1989). Interhemispheric connections differ between symmetrical and asymmetrical brain regions, Neuroscience 33: 525-533.

Steinmetz, H. \& Galaburda, A. M. (1991). Planum temporale asymmetry: In-vivo morphology affords a new perspective for neuro-behavioral research, Reading and Writing: An Interdisciplinary Journal 3: 331-343.

Whitehurst, G. D., Falco, F. L., Lonigan, C. J., Fischel, J. E., DeBarvshe, B. D., ValdezMenchaca, M. C. \& Caufield, M. (1988). Accelerating language development through picture book reading, Developmental Psychology 24: 552-559.

Wolf, P., Michel, G. F. \& Ovrut, M. (1990). Rate variables and automatized naming in developmental dyslexia, Brain and Language 39: 556-575.

Woodcock, R. W: (1987). Woodcock Reading Mastery Test-Revised. Circle Pines, MN: American Guidance.

Yeni-Komshian, G. H., Isenberg, D. \& Goldberg, H. (1975). Cerebral dominance and reading disability: Left visual field deficit in poor readers, Neuropsychologia 13: 83-94.

Zaidel, E. (1983). Disconnection syndrome as a model for laterality effects in the normal brain. In: J. B. Hellige (ed.), Cerebral hemisphere asymmetry: Method, theory, and application (pp. 95-151). New York: Praeger.

Address for correspondence: Dr Michael Rastetter, Department of Communication Sciences and Disorders, School of Allied Health Sciences, Belk Building, East Carolina University, Greenville, NC 27858-4353, USA

Phone: (919) 328 4404; Fax: (919) 3284470 